\title{
Characterization of tethered equine chorionic gonadotropin and its deglycosylated mutants by ovulation stimulation in mice
}

\author{
Kwan-Sik Min ${ }^{1,2^{*}}$, Jong-Ju Park', Munkhzaya Byambaragchaa ${ }^{1}$ and Myung-Hwa Kang ${ }^{3}$
}

\begin{abstract}
Background: To directly assess the biological role of oligosaccharides in recombinant equine chorionic gonadotropin (rec-eCG) functioning, cDNA encoding the full-length eCG $\beta$-subunit was fused with the mature protein part of the asubunit, and we examined the expression levels of deglycosylated eCG mutants, the ovulation rate for deglycosylated mutants in C57BL/6 mice.

Results: The characterizations of heterodimeric and tethered mutants were studied following their respective secretions in culture medium, molecular weight and ovulation in vivo. Rec-eCG variants containing mutations at glycosylation sites at Asn82 of the a-subunit (eCG $\beta / a \Delta 82$ ) and Asn13 of the $\beta$-subunit (eCG $\beta \Delta 13 / a$ ) were not efficiently secreted into the culture medium from transfected cells. Western blot analysis revealed that the receCG $\beta / a$ proteins have an approximate broad range of molecular weights of $40-46 \mathrm{kDa}$. Three rec-eCG mutantsa deglycosylated site at Asn56 of the a-subunit (eCG $\beta / a \Delta 56)$, a deletion of the C-terminal region of the $\beta$-subunit (eCG $\beta-D / a)$, and the double mutant (eCG $\beta-D / a \Delta 56)$ - turned out to have clearly lower (approximately 4-23 kDa) molecular weights. Protein N-glycosydase F (PNGase F) treatment markedly decreased the molecular weight to approximately 2-10 kDa. Normal oocytes were significantly more abundant in the natural eCG-treated group than in mutant rec-eCG-treated groups. In particular, numbers of nonfuntional oocytes were remarkably lower in all rec-eCG groups.
\end{abstract}

Conclusions: Our results indicate that the ovulation rates of oocytes are not affected by the deglycosylated rec-eCG $\beta$ / a mutant proteins. There are around 20\% non-functional oocytes with natural eCG and only $2 \%$ with the rec-eCGs tested. These results provide insight into the molecular mechanisms underlying the production of rec-eCG hormones with excellent bioactivity in vivo.

Keywords: Rec-eCG, Glycosylated sites, Ovulation rate

\section{Background}

Chorionic gonadotropin (CG) is a placental hormone that maintains the corpus luteum (CL) during pregnancy [1]. CG exist only in primates and equidaes and not in the other mammals. Gonadotropins are heterodimeric

\footnotetext{
* Correspondence: ksmin@hknu.ac.kr

${ }^{1}$ Animal Biotechnology, Graduate School of Future Convergence Technology, Institute of Genetic Engineering, Hankyong National University, Ansung 17579, Korea

2Department of Animal Resource Science, Hankyong National University, Ansung 17579, Korea

Full list of author information is available at the end of the article
}

glycoprotein hormones, consisting of dissimilar $\alpha$ - and $\beta$ subunits that are noncovalently complexed [2]. The $\alpha$-subunit of the glycoproteins is common for luteinizing hormone (LH), follicle-stimulating hormone (FSH), and thyroid-stimulating hormone (TSH) in a given species [3].

Equine CG (eCG) is a unique member of the gonadotropin family because it exhibits both LH- and FSH-like activities in non-equid species $[4,5]$. The $\beta$-subunits of eCG and equine LH (eLH), being translated from the same gene, have an identical primary structure [6, 7]. Thus, eCG may be an ideal model for studying the structure-function

(c) The Author(s). 2019 Open Access This article is distributed under the terms of the Creative Commons Attribution 4.0 International License (http://creativecommons.org/licenses/by/4.0/), which permits unrestricted use, distribution, and 
relations of gonadotropins because it possesses properties of both its pituitary and placental counterparts $[8,9]$. The difference between eCG and eLH lies in the structure of their carbohydrates, which are sialylated and sulfated in $\mathrm{LH}$ but only sialylated in CG [10, 11]. eCG is secreted from binucleate trophoblastic cells in endometrial cups, into maternal blood plasma during the first half of equine gestation. These cells get detached from the chorionic girdle of the conceptus between days 37 and 120 of pregnancy [12-14].

eCG administration has also been associated with an increase in ovulation rate [15], particularly in early-postpartum cows [16]. The standard dose of eCG required to promote single ovulation generally ranges between 200 and $1000 \mathrm{IU}$, whereas the dose necessary to induce superovulation is approximately $2500 \mathrm{IU}$ [17]. Similarly, eCG administration to sheep has been demonstrated to significantly increase the level of proteins FSH receptor (FSHR) and gonadotropin-releasing hormone receptor (GnRHR) secreted by oocytes [18]. Thus, eCG enhances maturation and stimulates FSHR, LHR, and GnRHR expression. In some studies on the secretion and activity of recombinant eCG (rec-eCG) in mammalian cells, deletion of carboxy-terminal peptides (CTPs) from dimeric eCG induced a $50 \%$ decrease in the secretion of the truncated hormone as compared to the wildtype [19]. FSH activity strongly depends on amino acid residues (aa) 102-104 of the eCG $\beta$-subunit [20], and correct folding and FSH activity are conferred by aa 104-109 of the eCG $\beta$-subunit [9].

Some studies have revealed that glycosylation of $\alpha$ subunit position 52 in human FSH (hFSH) [21], human chorionic gonadotropin (hCG) [22], and hTSH [23] is important for signal transduction, because cAMP or steroid formation is not stimulated, while the binding activity with FSHR was enhanced by 2- to 3-fold [24]. Thus, receptor binding and signal transduction are dissociable functions involving different sites on the FSH glycoprotein. Various studies suggest that CTPs of the deletion-containing (aa 115-145) hCG $\beta$-subunit $[25,26]$, and deletion-containing (aa 122-145) hCG [27] are not important for receptor binding or in vitro signal transduction. Nontheless, the truncated form of hCG $\beta$ lacking aa 101-145 is the shortest form of the subunit known to retain biological activity [28]. In $\mathrm{eLH}$, the deletion containing (aa 121-149) $\beta$-subunit is incapable of subunit association and receptor binding [29]. These results are consistent with findings of our previous research into the effects of deglycosylated rec-eCG mutants on estradiol and progesterone stimulation of rat granulosa cells and Leydig cells [5, 30].

To investigate the functional contribution of oligosaccharides in rec-eCGs and of carboxy-terminal extension (aa 114-149) of the eCG $\beta$-subunit, we created a total of 20 expression vectors encoding 11 heterodimeric eCGs and nine tethered eCGs. We produced rec-eCG $\alpha / \beta$ and eCG $\beta / \alpha$ proteins in $\mathrm{CHO}-\mathrm{K} 1$ cells, characterized these proteins' biological activities in vivo. Our results indicate that the loss of glycosylation at site Asn82 of the $\alpha$-subunit and at Asn13 of the $\beta$-subunit plays a pivotal role in secretion into the culture medium of CHO-K1 mammalian cells. Deglycosylated rec-eCGs showed a high oocyte ovulation rate in vivo.

\section{Results \\ Quantities of heterodimeric rec-eCG $\alpha / \beta$ and tethered rec- eCG $\beta / a$ proteins}

Oligosaccharide-directed mutagenesis was carried out examine the functional importance of oligosaccharides in eCG bioactivity. The eCG $\alpha$-subunit contains two Nlinked glycosylation sites at aa positions 56 and 82 . The eCG $\beta$-subunit contains one $\mathrm{N}$-linked glycosylation site at aa position 13 and approximately $11 \mathrm{O}$-linked glycosylation sites in the $\mathrm{C}$-terminal region. Thus, we constructed 20 expression vectors encoding 11 heterodimeric eCG mutants and nine tethered eCG mutants, respectively (Fig. 1).

The expression vectors were transiently transfected into cells and the culture supernatant was collected at $72 \mathrm{~h}$ after transfection. Stable colonies resistant to G418 were selected, and rec-eCGs secreted into the serum-free medium were collected and concentrated. The rec-eCGs were quantified by a pregnant mare serum gonadotropin (PMSG) enzyme-linked immunosorbent assay (PMSG ELISA). Although the rec-eCG protein was detected at a low concentration when it contained Asn13 in the eCG $\beta$ subunit, the protein (deglycosylated mutant) was nearly undetectable when it contained a mutation of Asn82 in the eCG $\alpha$-subunit and a mutation of Asn13 in the eCG $\beta$ subunit (Fig. 2a, b). Expression levels of the heterodimeric rec-eCGs $(\alpha / \beta, \alpha \Delta 56 / \beta, \alpha / \beta-D$, and $\alpha \Delta 56 / \beta-D)$ were $273 \pm 38.1,313 \pm 53.5,304 \pm 47.1$, and $294 \pm 28.3 \mathrm{ng} / \mathrm{mL}$, respectively. Expression levels of heterodimeric $\alpha \Delta 82 / \beta$ and $\alpha / \beta \Delta 13$ were $21 \pm 2.5$ and $80 \pm 23.8 \mathrm{ng} / \mathrm{mL}$, respectively. These levels were slightly lower for the tethered receCGs. The secreted quantities of rec-eCG $\beta / \alpha, \beta / \alpha \Delta 56$, $\beta$ $\mathrm{D} / \alpha$, and $\beta-\mathrm{D} / \alpha \Delta 56$ were $136 \pm 13.7,255 \pm 28.3,154 \pm$ 30.3 , and $135 \pm 8.8 \mathrm{ng} / \mathrm{mL}$, respectively. Nevertheless, the secretion pattern was the same as that of dimeric eCG. These results indicate that a loss of glycosylation at site Asn82 of the $\alpha$-subunit and at Asn13 of the $\beta$-subunit plays a pivotal role in secretion into the culture medium from CHO-K1 cells. On the other hand, deletion of the eCG $\beta$-subunit CTP did not affect the secretion into the culture medium from $\mathrm{CHO}-\mathrm{K} 1$ cells. We also compared the expression between mutants eCG $\beta / \alpha$ and myc eCG $\beta /$ $\alpha$; the latter contains a myctag (Fig. 2c). The expression levles of these proteins were nearly the same. 


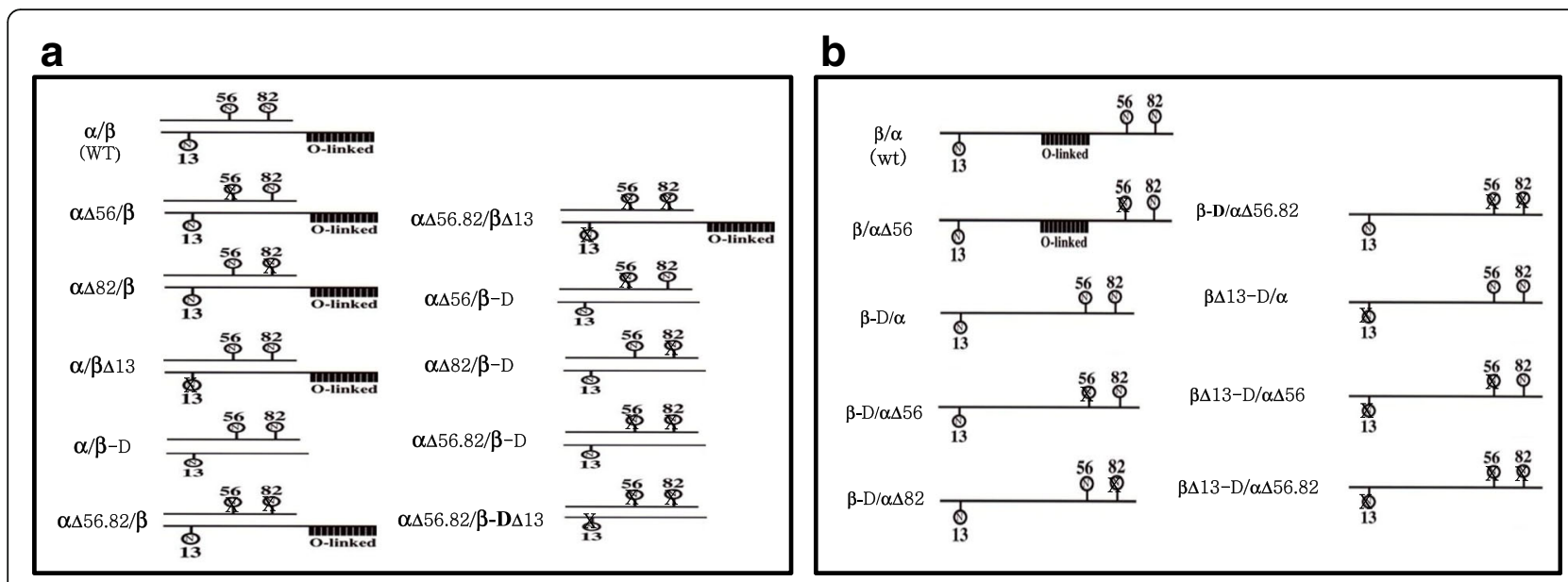

Fig. 1 A schematic diagram of rec-eCGa/ $\beta$ mutants (a) and rec-eCG $\beta /$ a mutants (b). The wild-type protein and mutants with changed $N$ - and O-linked oligosaccharide sites on eCG are shown. The Asn56 and 82 codons in the a-subunit were replaced by Gln or the CTP carrying O-linked oligosaccharides in the eCG $\beta$-subunit was deleted by PCR mediated site-directed mutagenesis. The circle " $\mathrm{N}$ " denotes an N-linked oligosaccharide, " $\mathrm{X}$ " indicates the absence of an oligosaccharide, and "O-linked" represents an O-linked oligosaccharide. A total of 20 expression vectors (for 11 heterodimeric eCGs and nine tethered eCGs) were constructed (plasmids encoding heterodimeric eCGs were designated as pAB-eCGa/ $\beta, p A B-a \Delta 56 / \beta, p A B-a \Delta 82 / \beta, p A B-a / \beta$ $\Delta 13, p A B-\alpha / \beta-D, p A B-a \Delta 56,82 / \beta, p A B-a \Delta 56 / \beta \Delta 13, p A B-a \Delta 56 / \beta-D$, pAB-a $\Delta 82 / \beta-D, p A B-a \Delta 56.82 / \beta-D$, and pAB- $a \Delta 56.82 / \beta \Delta 13$; plasmids encoding tethered eCGs were designated as pcDNA3-eCG $\beta / a$, pcDNA3- $\beta / a \Delta 56$, pcDNA3- $\beta-D / a, p c D N A 3-\beta-D / a \Delta 56, p c D N A 3-\beta-D / a \Delta 82, p c D N A 3-\beta-D / a \Delta 56.82$, pcDNA3- $\beta \Delta 13-D / a, p c D N A 3-\beta \Delta 13-D / \alpha \Delta 56$, and $p c D N A 3-\beta \Delta 13-D / a \Delta 56.82)$

\section{Western blot analysis of rec-eCG $\beta /$ a glycosylation mutants}

Next, we studied the tethered rec-eCG mutants to determine molecular weight and biological activity. By western blot analysis, we found an approximate range of molecular weight of $40-46 \mathrm{kDa}$ for rec-eCG $\beta / \alpha$, as shown in Fig. 3a. Rec-eCG $\beta / \alpha \Delta 56$, without N-linked oligosaccharides at Asn56 of the $\alpha$-subunit, was reduced to approximately $37-42 \mathrm{kDa}$, a decrease of $\sim 3-4 \mathrm{kDa}$. Rec-eCG $\beta-\mathrm{D} / \alpha$, with a deletiion of 35 aa including the O-glycosylated CTP of the $\beta$-subunit, remarkably diminished to approximately $27 \mathrm{kDa}$. The molecular weight of the double mutants (receCG $\beta-\mathrm{D} / \alpha \Delta 56)$ decreased to $\sim 23 \mathrm{kDa}$. After deglycosylation treatment with protein $\mathrm{N}$-glycosydase $\mathrm{F}$ (PNGase F), the molecular weights of rec-eCG $\beta / \alpha, \beta / \alpha \Delta 56, \beta-D / \alpha$, and $\beta-\mathrm{D} / \alpha \Delta 56$ decreased to approximately $30-36,33,19$, and $19 \mathrm{kDa}$, respectively (Fig. 3b). These results indicated that oligosaccharides were largely modified in rec-eCGs produced in $\mathrm{CHO}-\mathrm{K} 1$ cells and in the mutant proteins that were deglycosylated in the $\mathrm{N}$-linked and O-linked regions of eCG $\alpha$ - and $\beta$-subunits, confirming the loss of oligosaccharide chains.

\section{In vivo biological activity of rec-eCG mutants}

To test the in vivo activity of natural eCG and of rec-eCG derivatives, we examined oocyte ovulation. The numbers of normal ovulated oocytes in the natural-eCG group were $22.6 \pm 2.9$ as presented in Table 1 . By contrast, the other groups $(\beta / \alpha, \beta / \alpha \Delta 56, \beta-D \alpha$, and $\beta-D / \alpha \Delta 56)$, which were injected with rec-eCG proteins produced $13.5 \pm 1.3,14.8 \pm$ $1.2,14 \pm 1.8$, and $15 \pm 0.6$ oocytes, respectively. The number of normal oocytes after treatment with natural eCG was higher relative to the rec-eCG groups. Nonetheless, there were no differences among the rec-eCG groups. We also examined the nonfunctional oocytes which were detected in the natural-eCG-treated group (Additional file 1: Figure S1). Nearly the same numbers of nonfunctional oocytes were found in the rec-eCG-treated groups. These results meant that the rec-eCG proteins produced in this study had full activity and were capable of inducing ovulation.

\section{Discussion}

We examined the biological roles of $\mathrm{N}$-linked oligosaccharides and the O-linked CTP of eCG, as well as ovulation induction, in vivo by means of rec-eCG generated by site-directed mutagenesis. Another study [31] on rechCG suggest that mutagenesis of Asn at position 52, which is linked to an oligosaccharide, does not affect secretion of the mutant subunit. In contrast, the loss of the oligosaccharide at position 78 was found to cause the mutant subunit to be degraded quickly, and $<20 \%$ was secreted. The molecular weights of secreted wildtype hCG and mutant protein hCG $\alpha \Delta 52 / \beta$ turned out to be 28 and $22 \mathrm{kDa}$, respectively. Furthermore, some researchers reported that the absence of both N-linked units (Asn13 and Asn30) in the hCG 3 -subunit slows secretion by 2-2.4-fold [32]. As for rec-hTSH, wild-type $\mathrm{TSH}$ has a molecular weight of $\sim 38 \mathrm{kD}$, whereas the TSH single-site mutant (TSH $\alpha 1$ or $\mathrm{TSH} \alpha 2)$ and $\mathrm{TSH}$ double mutant (TSH $\alpha 1+\alpha 2)$ are approximately 35 and $31 \mathrm{kDa}$, respectively [23]. Our results are consistent with those of other studies, suggesting that secretion into the 

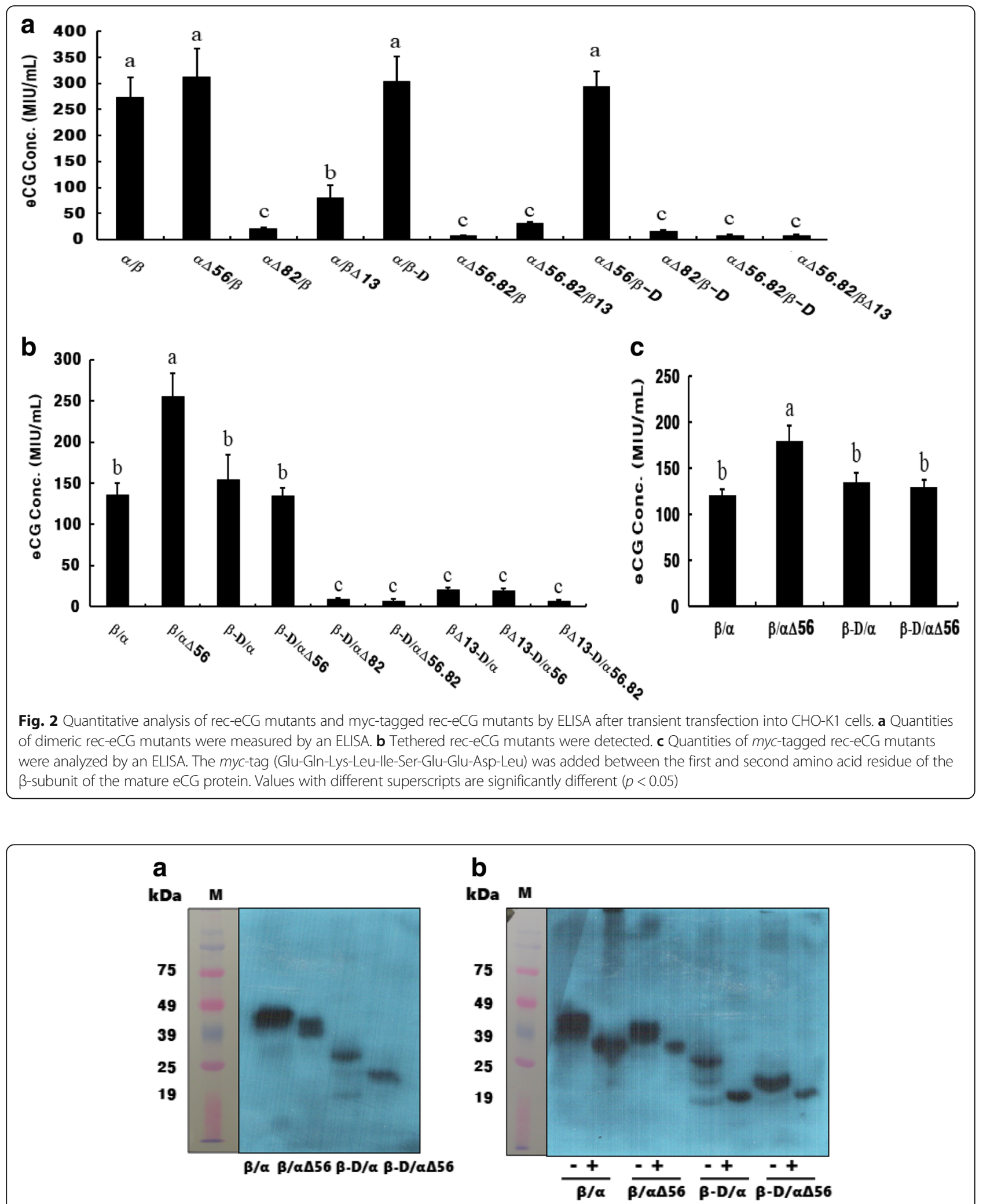

Fig. $\mathbf{3}$ Western blot analysis of tethered rec-eCG mutants. a Rec-eCG mutants were expressed in CHO-K1 cells. The proteins in conditioned media were collected, separated by SDS-PAGE, and transferred to a blotting membrane. The proteins were detected with antibodies against the myc-tag. b Proteins for western blotting were also treated with $N$-GlycosidaseF. Lane 1: $\beta / a$, Lane 2: $\beta / a \Delta 56$, Lane 3: $\beta-D / a$, Lane 4: $\beta$-D/a $\Delta 56$,-: not treated, +: treated with N-Glycosidase-F 
Table 1 Superovulation of mouse oocytes between natural-eCG and tethered rec-eCG $\beta /$ a deglycosylated mutants

\begin{tabular}{|c|c|c|c|}
\hline & \multicolumn{3}{|l|}{ No. Oocytes } \\
\hline & Functional & Nonfunctional & Nonfunctional relative to total oocytes (\%) \\
\hline PMSG $(n=9)$ & $22.6 \pm 2.9 \mathrm{~A}$ & $4.78 \pm 0.5 a$ & 21.2 \\
\hline rec-eCG $\beta / a(n=6)$ & $13.5 \pm 1.3 B$ & $0.33 \pm 0.2 b$ & 2.4 \\
\hline rec-eCG $\beta / a \Delta 56(n=6)$ & $14.8 \pm 1.2 B$ & ob & 0 \\
\hline rec-eCGB-D/a $(n=6)$ & $14.0 \pm 1.8 \mathrm{~B}$ & $0.33 \pm 0.3 b$ & 2.4 \\
\hline rec-eCGß-D/a $\Delta 56(n=6)$ & $15.0 \pm 0.6 B$ & ob & 0 \\
\hline
\end{tabular}

The mice were superovulated by injection of $10 \mathrm{IU}$ of PMSG or rec-eCGs and then $10 \mathrm{IU}$ hCG after $48 \mathrm{~h}$, and ovulated oocytes were collected into an oviduct ampulla after $13 \mathrm{~h}$ as described in Methods. $1 \mathrm{IU}$ was assumed to be $100 \mathrm{ng}$ according to the conversion factor of the suggested assay protocol corresponding PMSG by standard curve. The ovulated oocytes were determined under microscope as shown in Additional file 1: Figure S1. The percentage of nonfunctional relative to total oocytes was around $20 \%$ with natural eCG and only around $2 \%$ with rec-eCGs used

Values are expressed as mean \pm SEM for at least three independent experiments

A-B, a-bValues with different superscripts are significantly different $(p<0.05)$

culture medium is controlled by the specific glycosylation sites (Asn82 in the $\alpha$-subunit and Asn13 in the $\beta$-subunit). Thus, the Asn-linked oligosaccharides of eCG $\alpha$ - and $\beta$ subunits may have site-specific functions with respect to secretion. The secreted single-chain eCG in COS-7 cells is detectable as a doublet of 46 and $44 \mathrm{kDa}$ [9]. We confirmed that the loss of oligosaccharide chains greatly decreases the molecular weight of the deglycosylated $\mathrm{N}$ linked and O-linked rec-eCG $\alpha / \beta$ mutants.

Regarding in vitro biological activity, some studies have revealed that glycosylation of Asn52 of the hFSH $\alpha$-subunit results in a significant decrease in potency (to $26 \%$ of the wild-type level) [21] of signal transduction, but binding activity is enhanced 2- to 3-fold [24]. Thus, they proposed that receptor binding and signal transduction are dissociable functions involving different sites on the FSH glycoprotein. The $\alpha$-subunit Asn52 oligosaccharide has a disproportionate role in signal transduction, and the amino acid sequence near $\beta$-subunit Asn24 functions in both binding and signal transduction [33]. In hCG, the Asn52 oligosaccharide has been found to be important for signal transduction; without this oligosaccharide, cAMP stimulation and steroid formation fail [22]. Deletion of oligosaccharide units from either site 1 (Asn52) or site 2 (Asn78) of the $\alpha$-subunit increased the biological activity of the dimer in that study by approximately $30 \%$. Nevertheless, carbohydrate unit at both sites (Asn52 and Asn78) of the hTSH $\alpha$-subunit significantly reduces cAMP formation (by $\sim 70 \%$ ) and T3 secretion (by 40\%) as compared to wildtype hTSH [23]. Furthermore, the CTP of hCG $\beta$ does not interact directly with the choriogonadotropin hormone receptor (LH-CGR) complex and apparently does not influence the tertiary structure or folding of the $\beta$-subunit $[22,26,31]$. Besides, we have found that Asn56 of the eCG $\alpha$-subunit does not enhance agonist stimulation internalization through rat LH/CGR (rLH/CGR) and rFSHR [34].

Various studies indicate that rec-eCG yield the formation and secretion of stable heterodimeric eCG in infected Sf9 cells [35] and COS-7 cells [36], and that rec-eCG has the same thermal stability as natural pituitary LH [37]. Olinked oligosaccharides of the CTP in the hCG $\beta$-subunit play only a minor role in receptor binding and signal transduction in vitro. By contrast, these oligosaccharides are critical for the in vivo biological response, suggesting that truncated hCG results in significantly fewer ovulated oocytes at doses of 70 and $210 \mathrm{ng}$ [22]. We have previously reported that heterodimeric rec-eCG $\alpha / \beta$ exert $\mathrm{LH}$ - and FSH-like activities similar to those of native eCG in in vitro bioassays of primary cultured rat Leydig and granulosa cells, respectively [5], and the same is true for tethered eCG $\beta / \alpha$ [30]. We have also shown previously that rec-eCG of nonequid species has both $\mathrm{LH}$ - and FSH-like activities in in vitro experiments on cells expressing $\mathrm{rLH} /$ CGR and rFSHR [34] and in terms of receptor function [38]. Nevertheless, no studies have examined the ovulation rate in mice under the influence of rec-eCG derivatives. Here, we suggest that the ovulation rates in mice may not be affected by the deglycosylating mutations. Nevertheless, it is impossible to compare potencies by means of only one dose, 10 IU injection. Thus, biological activity of rec-eCG derivatives slightly differs in vitro and in vivo.

\section{Conclusions}

Thus, secretion into the culture medium in rec-eCG $\beta / \alpha$ is controlled by specific glycosylation sites: Asn 82 of the $\alpha$ subunit and Asn 13 of the $\beta$-subunit. The Asn-linked oligosaccharides of eCG $\alpha$ - and $\beta$-subunits have site-specific functions with respect to secretion. Besides, we confirmed by removal of oligosaccharide chains that the molecular weight was decreased by deglycosylation of the $\mathrm{N}$-linked and O-linked eCG $\alpha$ - and $\beta$-subunits. The nonfunctional oocytes were around $20 \%$ in the natural eCG-treated mice. However there are only around $2 \%$ with the rec-eCG derivatives tested. We also suggest that the differences between rec-eCG and natural-eCG could rather be due to the nature of the injected hormone. Therefore, rec-eCG $\beta / \alpha$ derivatives have a good potential to produce functional oocytes with a much smaller number nonfunctional oocytes. 


\section{Methods \\ Materials}

The oligonucleotides employed in this study were synthesized by Genotech (Daejon, Korea). The following reagents and materials were also used: restriction enzymes, polymerase chain reaction reagents, and the DNA ligation kit were purchased from Takara (Tokyo, Japan). CHO-K1 cells were obtained from the Japanese Cancer Research Resources Bank (Tokyo, Japan). Ham's F-12 medium, Opti-MEM I, serum-free CHO-S-SFM II, geneticin, and Lipofectamine 2000 were bought from Gibco BRL (Grand Island, NY, USA), and fetal bovine serum from Hyclone Laboratories (Logan, UT, USA). The QIAprep-Spin plasmid kit and RNeasy columns were acquired from QIAGEN, Inc. (Hilden, Germany), whereas the Pro-Prep ${ }^{\mathrm{Tm}}$ protein extraction solution from Intron Biotechnology (Seoul, Korea). The Lumi-Light western blot kit was bought from Roche (Basel, Switzerland), and the pcDNA3 mammalian expression vector, PNGase F, and TRIzol reagent from Invitrogen (Carlsbad, CA, USA). The PMSG ELISA kit was purchased from DRG International, Inc. (Mountainside, NJ, USA), Centriplus Centrifugal Filter Devices from Amicon Bio separations (Merck, Billerica, MA, USA), and an anti-myc antibody from Santa Cruz Biotechnology (Dallas, Texas, USA). A peroxidase-conjugated anti-mouse IgG antibody was acquired from Bio-Rad (Hercules, CA, USA), whereas pregnantmare serum gonadotropin (eCG) from Sigma-Aldrich Corp. (St. Louis, MO, USA), as were all other reagents. All experimental designs and procedures were in compliance with the approved Guidelines for Animal Experiments of Hankyong National University, Korea, and were approved by the Animal Care and Use Committee of Hankyong National University, Korea (Approval ID: 2015-8).

\section{Construction of heterodimeric eCGa/ $\beta$ and tethered eCG $\beta / \alpha$}

The heterodimeric eCG $\alpha / \beta$ and its mutants were created using the pABWN vector as previously reported [5]. Additionally, cDNA encoding the tethered rec-eCG $\beta / \alpha$ was inserted into the pcDNA3 vector and served as a template to construct mutants in which Asn (codon AAC) of the glycosylation site was substituted with Ala (codon CAG) or the CTP was deleted in the $\beta$-subunit as reported elsewhere [30]. The same method was used to add a myctag (Glu-Gln-Lys-Leu-Ile-Ser-Glu-Glu-Asp-Leu) between the first and second amino acid residues of the $\beta$-subunit of the mature eCG protein [38]. Site-directed mutagenesis was performed with three primers in a single-step PCR [5]. The primers employed in the experiment are summarized in Table 2). The first PCR was carried out with primers 2 and 3. DNA fragments were spliced and subjected to a second PCR involving primers 1 and 12 to generate tethered eCGs. The schematic diagrams of heterodimeric rec$\mathrm{eCG} \alpha / \beta$ and tethered rec-eCG $\beta / \alpha$ mutants are depicted in Fig. 1.
We mutated Asn to Gln at each glycosylation site (Asn56, Asn82, Asn13, deletion of the $\beta$-subunit CTP region with one site and a combination). These fragments were digested with EcoRI and SalI and ligated into eukaryotic expression vector pcDNA3. The plasmid DNAs were purified and sequenced in both directions by automated DNA sequencing to ensure that the correct mutations were introduced. A total of 20 expression vectors (11 heterodimeric eCGs and nine tethered eCGs) were constructed (plasmids expressing heterodimeric eCGs were designated as pAB-eCG $\alpha / \beta$, pAB- $\alpha \Delta 56 / \beta$, pAB- $\alpha \Delta 82 / \beta$, pAB- $\alpha / \beta \Delta 13, \quad$ pAB- $\alpha / \beta-D, \quad$ pAB $-\alpha \Delta 56,82 / \beta, \quad$ pAB- $\alpha \Delta 56 /$ $\beta \Delta 13$, pAB- $\alpha \Delta 56 / \beta-\mathrm{D}, \mathrm{pAB}-\alpha \Delta 82 / \beta-\mathrm{D}, \mathrm{pAB}-\alpha \Delta 56.82 / \beta-\mathrm{D}$, and pAB- $\alpha \Delta 56.82 / \beta \Delta 13$; plasmids expressing tethered eCGs were designated as pcDNA3-eCG $\beta / \alpha$, pcDNA3- $\beta$ / $\alpha \Delta 56$, pcDNA3- $\beta-\mathrm{D} / \alpha$, pcDNA3- $\beta-\mathrm{D} / \alpha \Delta 56$, pcDNA3- $\beta-\mathrm{D} /$ $\alpha \Delta 82$, pcDNA3- $\beta-D / \alpha \Delta 56.82$, pcDNA3- $\beta \Delta 13-D / \alpha$, pcDNA3$\beta \Delta 13-\mathrm{D} / \alpha \Delta 56$, and pcDNA3- $\beta \Delta 13-\mathrm{D} / \alpha \Delta 56.82)$ as previously reported $[5,30,34]$.

\section{Cell culture and functional expression}

Expression vectors were transfected into $\mathrm{CHO}-\mathrm{K} 1$ cells by the liposome transfection method as described in ref. [30]. The transfected cells were cultured for $48 \mathrm{~h}$ in a serum-free medium (CHO-S-SFM-II) and then harvested and centrifuged at $100,000 \times g$ for $10 \mathrm{~min}$. The supernatant was collected and stored at $-20{ }^{\circ} \mathrm{C}$ until the assay. Six to eight pools of stably transfected cells were selected by incubating the cells in a growth medium [Ham's F12 medium with $10 \%$ of fetal calf serum, penicillin $(100 \mathrm{IU} / \mathrm{mL})$, streptomycin $(100 \mu \mathrm{g} / \mathrm{mL})$, glutamine $(2 \mathrm{mM})$, and G418 $(800 \mu \mathrm{g} /$ $\mathrm{mL})$ ] for 2-3 weeks after transfection, as previously reported [30]. The culture medium was centrifuged at 100, $000 \times g$ for $10 \mathrm{~min}$ to remove cell debris. The supernatant was collected and concentrated in an Amicon Stirred cell concentrator and stored at $-20^{\circ} \mathrm{C}$ until the assay.

\section{Quantification of rec-eCG proteins}

The plasmids encoding dimeric eCG and single-chain eCG were transiently transfected into $\mathrm{CHO}-\mathrm{K} 1$ cells, and the culture media were collected at $72 \mathrm{~h}$ after transfection, and rec-eCG was quantified with the PMSG ELISA kit (DRG Diagnostics). Briefly, the collected medium was centrifuged to remove cell debris at $5000 \mathrm{rpm}$ for $3 \mathrm{~min}$. The supernatant was collected and stored at $-20^{\circ} \mathrm{C}$ until analysis. The PMSG standard and rec-eCG samples $(100 \mu \mathrm{L})$ were dispensed into wells of a plate coated with a monoclonal antibody against a unique antigenic site on the eCG molecule. The plate was incubated for $60 \mathrm{~min}$ at room temperature without agitation. Then, we briskly shook out the contents of the wells and rinsed them three times with distilled water. After that, $100 \mu \mathrm{L}$ of a anti-PMSG antibody conjugated to horseradish peroxidase was added into each 
Table $\mathbf{2}$ List of primers used for the construction of tethered eCG mutants

\begin{tabular}{|c|c|c|c|}
\hline & Primer name & Location & Primer Sequence \\
\hline 1 & eCG $\beta / a \beta$-subnuit & - & $\begin{array}{l}\text { 5'- TGAATTCACCATGGAGACGGTCCAG -3' } \\
\text { Eco } \bar{R} \text { I site }\end{array}$ \\
\hline 2 & myc eCG $\beta / a$ reverse & - & 5'- TCCATCAGGAAAAGAAGTCTTTATTGG -3' \\
\hline 3 & myc eCG $\beta / a$ forward & - & 5'- ATAAAGACTTCTIITCCTTGATGGAGAG -3' \\
\hline 4 & $\mathrm{eCG} \beta / a \Delta 56$ reverse & a 56 & 5'- TGAGGTGATCTGCTTTGGGACCAACAT -3' \\
\hline 5 & $\mathrm{eCG} \beta / a \Delta 56$ forward & a 56 & 5'- ATGTTGGTCCCAAAGCAGATCACCTCA -3' \\
\hline 6 & $\mathrm{eCG} \beta / a \Delta 82$ reverse & a 82 & 5'- GGCCTCCTTCTCAGCGGCCAGAGTGGCGTTGAT -3' \\
\hline 7 & $\mathrm{eCG} \beta / a \Delta 82$ forward & a 82 & 5'- ATCAACGCCACTCTGGCCGCTGAGAAGGAGGCC -3' \\
\hline 8 & $\mathrm{eCG} \beta \boldsymbol{\Delta} 13 / a$ reverse & $\beta 13$ & 5'- AGCAGCCAGAGTGGCGTTGATGGGCCGGCACAG -3' \\
\hline 9 & eCG $\beta \Delta 13 / a$ forward & $\beta 13$ & 5'- CTGTGCCGGCCCATCAACGCCACTCTGGCTGCT -3' \\
\hline 10 & eCG $\beta$-D/a reverse & $\beta: 121-149$ & 5'- TCCATCAGGAAAGGCCTGGGGGGCACAGGC -3' \\
\hline 11 & eCG $\beta-D / a$ forward & $\beta: 121-149$ & 5'- GCCCCCCAGGCCTTTCCTCATGGAGAGTTT -3' \\
\hline 12 & eCG $\beta / a$ a-subunit & - & $\begin{array}{l}\text { 5'- CCGTCGACITAAATCTTGTGGTGATAGCA -3' } \\
\text { Sal I site }\end{array}$ \\
\hline
\end{tabular}

well and incubated for $60 \mathrm{~min}$ at room temperature without agitation. The plate wells were rinsed five times, and residual water droplets were removed. A substrate solution $(100 \mu \mathrm{L})$ was next added and incubated for $30 \mathrm{~min}$ at room temperature. Finally, $50 \mu \mathrm{L}$ a stop solution was added to stop the enzymatic reaction. The absorbance of the product solution was read at $450 \mathrm{~nm}$ on a micro titer plate reader. The average absorbance of each standard was plotted against its corresponding concentration in a linear-log graph. We calculated the average absorbance of each sample to determine the corresponding PMSG value via simple interpolation by means of this standard curve. Finally, $1 \mathrm{IU}$ was assumed to be $100 \mathrm{ng}$ according to the conversion factor of the suggested assay protocol.

Detection of rec-eCGs by western blotting and enzymatic digestion of $\mathrm{N}$-linked oligosaccharides

For western blot analysis, samples of a concentrated medium were subjected to electrophores is under reducing conditions in sodium dodecyl sulfate (SDS) $12.5 \%$ polyacrylamide gels by the Laemmli method [39]. After SDS polyacrylamide gel electrophoresis (PAGE), the proteins were transferred to a polyvinylidene difluoride membrane $(0.2 \mu \mathrm{m})$ at $100 \mathrm{~V}$ for $2 \mathrm{~h}$ in a Mini Trans-Blot Electrophoretic Transfer cell. After blotting, the membrane was blocked with a $1 \%$ blocking reagent for $1 \mathrm{~h}$, and the monoclonal anti-myc antibody $(1: 5,000)$ was added for $2 \mathrm{~h}$ incubation. Next, the blot was washed to remove the unbound antibody, incubated with a secondary antibody (peroxidase-conjugated anti-mouse IgG antibody $37.5 \mu \mathrm{L} / 15 \mathrm{~mL}$ of the blocking solution) for 30 min, and washed. The membrane was then incubated for $5 \mathrm{~min}$ with $2 \mathrm{~mL}$ of the Lumi-Light substrate solution and placed with its protein side up on a plastic wrap. The membrane was covered with a second piece of the plastic wrap, and an $\mathrm{X}$ - ray film was exposed to the membrane for 1-10 min. The tethered rec-eCG protein was analyzed regarding removal of added glycans by $N$ glycosylation enzyme. To remove all $\mathrm{N}$-linked glycans, rec-eCG was incubated for $24 \mathrm{~h}$ at $37^{\circ} \mathrm{C}$ with PNGase $\mathrm{F}$ [ $2 \mu \mathrm{L}$ of the enzyme $(2.5 \mathrm{U} / \mathrm{mL})$ per $30 \mu \mathrm{L}$ of sample+ $8 \mu \mathrm{L}$ of $5 \times$ reaction buffer]. The reaction was stopped by boiling for $10 \mathrm{~min}$, and the samples were analyzed by SDS-PAGE and western blotting.

\section{In vivo biopotency}

This property of rec-eCG $\beta / \alpha$ proteins was evaluated by determining the ovulated-oocyte number. Oocytes were collected from 8-week-old B6D2F1 female mice. The mice were superovulated by injection of $10 \mathrm{IU}$ of PMSG or rec-eCGs and then $10 \mathrm{IU}$ hCG after $48 \mathrm{~h}$, and ovulated oocytes were collected into an oviduct ampulla after $13 \mathrm{~h}$. Cumulus cells were removed from the collected oocytes by means of $0.3 \%$ hyaluronidase. The oocytes were analyzed for several characteristics (e.g., cytoplasmic membrane, first polar body, and morphological features).

\section{Data and statistical analysis}

Values are given as mean \pm SEM. One-way ANOVA with Tukey's multiple-comparison test was conducted to compare the results between samples. In figures, superscripts indicate significant differences from a group $(p<0.05)$.

\section{Additional file}

Additional file 1: Figure S1. Functional and nonfunctional oocytes. (PPT $289 \mathrm{~kb}$ ) 


\section{Abbreviations}

CL: Corpus luteum; CTP: Carboxy-terminal peptides; FSH: Follicle-stimulating hormone; FSHR: FSH receptor; GnRHR: Gonadotropin releasing hormone receptor; LH: Luteinizing hormone; PMSG: Pregnant mare serum gonadotropin; rec-eCG: Recombinant equine chorionic gonadotropin; SDS-PAGE: Sodium dodecyl sulfate-polyacrylamide gel electrophoresis; TSH: Thyroid-stimulating hormone

\section{Acknowledgements}

The authors thank Dr. HW Seong for a helpful discussion.

\section{Authors' contributions}

JJP conducted the experiments. MB performed the ELISA analysis and interpretation of data. MHK and KSM wrote the main manuscript text and prepared the figures and supplementary file. All authors reviewed the final manuscript. All authors read and approved the final manuscript.

\section{Funding}

This work was financially supported by Korean Research Foundation Program (2018007794), Republic of Korea. The funders role was providing funding for the study and all other aspects of the project (design, collection, analysis, and interpretation of data and writing of the manuscript) was executed by the authors.

\section{Availability of data and materials}

The datasets used and analyzed in the current study are available from the corresponding author on reasonable request.

\section{Ethics approval and consent to participate}

Not applicable. All experimental designs and procedures were in compliance with the approved Guidelines for Animal Experiments of Hankyong National University, Korea and were approved by the Animal Care and Use Committee of Hankyong National University, Korea (Approval ID: 2015-8)

\section{Consent for publication}

Not applicable.

\section{Competing interests}

The authors declare that they have no competing interests.

\section{Author details}

'Animal Biotechnology, Graduate School of Future Convergence Technology, Institute of Genetic Engineering, Hankyong National University, Ansung 17579, Korea. ${ }^{2}$ Department of Animal Resource Science, Hankyong National University, Ansung 17579, Korea. ${ }^{3}$ Department of Food Science and Nutrition, Hoseo University, Asan 31499, Korea.

Received: 25 July 2018 Accepted: 22 July 2019

Published online: 13 August 2019

\section{References}

1. Talmadge K, Vamvakopoulos NC, Fiddes JC. Evolution of the gens for the $b$ subunits of human chorionic gonadotropin and luteinizing hormone. Nature. 1984;307:37-40.

2. Pierce JG, Parsons TF. Glycoprotein hormones: structure and function. Annu Rev Biochem. 1981;50:465-95.

3. Murphy BD, Martinuk SD. Equine chorionic gonadotropin. Endocr Rev. 1991;12:27-44

4. Chopineau M, Maurel MC, Combarnous Y, Durand P. Topography of equine chorionic gonadotropin epitopes relative to the luteinizing hormone and follicle-stimulating hormone receptor interaction sites. Mol Cell Endocrinol. 1993:92:229-39.

5. Min KS, Hattori N, Aikawa Jl, Shiota K, Ogawa T. Site-directed mutagenesis of recombinant equine chorionic gonadotropin/luteinizing hormone: differential role of oligosaccharides in luteinizing hormone- and folliclestimulating hormone-like activities. Endocr J. 1996:43:585-93.

6. Serman GB, Wolfe MW, Farmerie TA, Clay CM, Threadgill DS, Sharp DC, Nilson $\mathrm{JH}$. A single gene encodes the $\beta$-subunit of equine luteinizing hormone and chorionic gonadotropin. Mol Endocrinol. 1992;6:951-9.
7. Min KS, Shinozaki M, Miyazawa K, Nishimura R, Sasaki N, Shiota K, Ogawa T. Nucleotide sequence of eCGa-subunit cDNA and its expression in the equine placenta. J Reprod Dev. 1994;40:301-5.

8. Guillou F, Combarnous Y. Purification of equine gonadotropins and comparative study of their acid-dissociation and receptor-binding specificity. Biochim Biophys Acta. 1983:755:229-36.

9. Galet C, Guillou F, Foulon-Gauze F, Combarnous Y, Chopineau M. The $\beta 104-$ 109 sequence is essential for the secretion of correctly folded single-chain Ba horse LH/CG and for its activity. J Endocrinol. 2009;203:167-74.

10. Smith PL, Bousfield GR, Kumar S, Fiete D, Baenziger JU. Equine lutropin and chorionic gonadotropin bear oligosaccharides terminating with $\mathrm{SO}_{4}$-4GalNAc and Siaa2,3Gal, respectively. J Biol Chem. 1993;268:795-802.

11. Matsui T, Mizuochi T, Titani K, Okinaga T, Hoshi M, Bousfield GR, Sugino H, Ward DN. Structural analysis of N-linked oligosaccharides of equine chorionic gonadotropin and lutropin ß-subunits. Biochemistry. 1994:33:14039-48.

12. Boeta M, Zarco L. Luteogenic and luteotropic effects of eCG during pregnancy in the mare. Anim Reprod Sci. 2012;130:57-62.

13. Flores-Flores G, Velazquez-Canton E, Boeta M, Zarco L. Luteoprotective role of equine chorionic gonadotropin (eCG) during pregnancy in the mare. Reprod Dom Anim. 2014;49:420-6.

14. Conley AJ. Review of the reproductive endocrinology of the pregnant and parturient mare. Theriogenology. 2016;86:355-65.

15. Garcia-Ispierto I, Lopez-Helguera I, Martino A, Lopez-Gatius F. Reproductive performance of anoestrous high-producing dairy cows improved by adding equine chorionic gonadotrophin to a progesterone-based oestrous synchronizing protocol. Reprod in Dom Anim. 2012;47:752-8.

16. Rostami B, Niasari-Naslaji A, Vojgani M, Nikjou D, Amanlou H, Gerami A. Effect of eCG on early resumption of ovarian activity in postpartum dairy cows. Anim Reprod Sci. 2011;128:100-6.

17. Rensis FD, Lopez-Gatius F. Use of equine chorionic gonadotropin to control reproduction of the dairy cow: a review. Reprod Dom Anim. 2014;49:177-82

18. Wei SC, Gong ZD, Zhao HW, Liang HQ, Lai LJ, Deng YY. Equine chorionic gonadotropin influence on sheep oocyte in vitro maturation, apoptosis, and follicle-stimulating hormone receptor and luteinizing hormone receptor expression. Gene Mol Res. 2016;15:1-13.

19. Galet C, Menck L, Bourhis C, Chopineau M, Le-Griec G, Perrin A, Magallon T, Attal J, Viglietta C, Houdebine LM, Guillou F. Expression of a single $\beta$ a chain protein of equine LH/CG in milk of transgenic rabbits and its biological activity. Mol Cell Endocrinol. 2000;174:31-40.

20. Chopineau M, Martinat N, Galet C, Guillou F, Combarnous Y. B-Subunit 102 104 residues are crucial to confer FSH activity to equine LH/CG but are not sufficient to confer FSH activity to human CG. J Endocrinol. 2001:169:55-63.

21. Bishop LA, Robertson DM, Cahir N, Schofield PR. Specific roles for the asparagine-linked carbohydrate residues of recombinant human follicle stimulating hormone in receptor binding and signal transduction. Mol Endocrinol. 1994:8:722-31.

22. Matzuk MM, Keene $J$, Boime I. Site specificity of the chorionic gonadotropin N-linked oligosaccharides in signal transduction. J Biol Chem. 1989;264:2409-14.

23. Fares FA, Gruener N, Kraie MZ. The role of the asparagine-linked olgosaccharides of the a-subunit in human thyrotropin activity. Endocrinology. 1996:137:555-60.

24. Valove FM, Finch C, Anasti JN, Froehlich J, Flack MR. Receptor binding and signal transduction are dissociable functions requires different sites on follicle-stimulating hormone. Endocrinology. 1994;135:2657-61.

25. Chen W, Bahl OP. Recombinant carbohydrate variant of human choriogonadotropin $\beta$-subunit (hCG $\beta$ ) descarboxyl terminus (115-145). J Biol Chem. 1991;266:6246-51.

26. Matzuk MM, Hsueh AJW, Lapolt P, Tsafriri A, Keene JL, Boime I. Biological role of the carboxyl-terminal extension of human chorionic gonadotropin ß-subunit. Endocrinology. 1990;126:376-83.

27. El-Deiry S, Kaetzel D, Kennedy G, Nilson J, Puett D. Site-directed mutagenesis of the human chorionic gonadotropin beta-subunit: bioactivity of a heterologous hormone, bovine alpha-human des-(122-145) beta. Mol Endocrinol. 1989:3:1523-8.

28. Chen W, Puett D. Delineation via site-directed mutagenesis of the carboxylterminal region of human choriogonadotropin $\beta$ required for subunit assembly and biological activity. J Biol Chem. 1991;266:6904-8. 
29. Bousfield GR, Liu WK, Ward DN. Effects of removal of carboxyl-terminal extension from equine luteinizing hormone $(\mathrm{LH}) \beta$-subunit on $\mathrm{LH}$ and follicle-stimulating hormone receptor-binding activities and $\mathrm{LH}$ steroidogenic activity in rat testicular Leydig cells. Endocrinology. 1989; 124:379-87.

30. Min KS, Hiyama T, Seong HH, Hattori N, Tanaka S, Shiota K. Biological activities of tethered equine chorionic gonadotropin (eCG) and its deglycosylated mutants. J Reprod Dev. 2004;50:297-304.

31. Matzuk MM, Boime I. The role of the asparagine-linked oligosaccharides of the a subunit in the secretion and assembly of human chorionic gonadotropin. J Cell Bio. 1988;106:1049-59.

32. Matzuk MM, Boime I. Site-specific mutagenesis defines the intracellular role of the asparagine-linked oligosaccharides of chorionic gonadotropin $\beta$ subunit. J Biol Chem. 1988;26:17106-11.

33. Flack MR, Froehlich J, Bennet AP, Anasti J, Nisula BC. Site-directed mutagenesis defines the individual roles of the glycosylation sites on follicle-stimulation hormone. J Biol Chem. 1994;269:14015-20.

34. Park JJ, Seong HK, Kim JS, Byambarachaa M, Kang MH, Min KS. Internalization of rat FSH and LH/CG receptors by rec-eCG in CHO-K1 cells. Dev Reprod. 2017;21:111-20.

35. Legardinier S, Klett D, Poirier JC, Combarnous Y, Cahoreau C. Mammalianlike nonsialyl complex-type $\mathrm{N}$-glycosylation of equine gonadotropins in mimic $^{\text {TM }}$ insect cells. Glycobiology. 2005;15:776-90.

36. Chopineau M, Martinat N, Trospoux C, Marichatou H, Combarnous Y, Stewart F, Guillou F. Expression of horse and donkey LH in COS-7 cells: evidence for low FSH activity in donkey $\mathrm{LH}$ compared with horse $\mathrm{LH}$. J Endocrinol. 1997;152:371-7.

37. Legardinier S, Poirier JC, Klett D, Combarnous Y, Cahoreau C. Stability and biological activities of heterodimeric and single-chain equine $\mathrm{LH} /$ chorionic goandotropin variants. J Mole Endocrinol. 2008:40:185-98.

38. Min KS, Liu X, Fabritz JE, Jaquette J, Abell AN, Ascoli M. Mutations that induce constitutive activation and mutations that impair signal transduction modulate the basal and/or agonist-stimulated internalization of the lutropin/choriogonadotropin receptor. J Biol Chem. 1998;273:34911-9.

39. Laemmli UK. Cleavage of structural proteins during the assembly of the head of bacteriophage T4. Nature. 1970;227:680-5.

\section{Publisher's Note}

Springer Nature remains neutral with regard to jurisdictional claims in published maps and institutional affiliations.

Ready to submit your research? Choose BMC and benefit from:

- fast, convenient online submission

- thorough peer review by experienced researchers in your field

- rapid publication on acceptance

- support for research data, including large and complex data types

- gold Open Access which fosters wider collaboration and increased citations

- maximum visibility for your research: over $100 \mathrm{M}$ website views per year

At $\mathrm{BMC}$, research is always in progress.

Learn more biomedcentral.com/submissions 